\title{
Erratum to: Predictors of recurrence in the management of chordoid meningioma
}

\author{
Winward Choy $^{1} \cdot$ Leonel Ampie $^{1} \cdot$ Jonathan B. Lamano $^{1} \cdot$ Kartik Kesavabhotla $^{1}$. \\ Qinwen $\mathrm{Mao}^{2} \cdot$ Andrew T. Parsa ${ }^{1} \cdot$ Orin Bloch $^{1}$
}

Published online: 22 October 2015

(c) Springer Science+Business Media New York 2015

\section{Erratum to: J Neurooncol DOI 10.1007/s11060-015-1940-9}

In the original publication there are errors in the captions to Figs. $2-4$ and in the references to these figures in the text. The captions should have read as follows:

Fig. 2 Characteristic histological features of chordoid meningiomas. a Chordoid meningioma demonstrating chord-like arrangement of eosinophilic tumor cells with a background of mucoid matrix (hematoxylin-phoxyn-saffron: HPS, bar $100 \mu \mathrm{m})$. b Alcian Blue positivity within the mucoid matrix (Alcian Blue/HE, bar $100 \mu \mathrm{m}$ ). Reprinted from Di Ieva et al. [9], with permission from John Wiley and Sons

Fig. 3 Kaplan-Meier curve for all patients included within the study. 3- and 5-year PFS was 76.0 and $67.5 \%$, respectively
Fig. 4 Kaplan-Meier analysis of recurrence free survival following either gross (GTR) to subtotal (STR) resection. Greater extent of surgery was associated with improved rates of tumor control. For GTR, 3- and 5-year PFS was 85.3 and $80.8 \%$, respectively. For STR, 3- and 5-year PFS was 50.7 and $33.8 \%$, respectively, $\mathrm{p}<0.001$

The references to these three figures in the text should have been placed as follows:

Figure 2 should have been cited in the Introduction after the citation of Kepes et al. [4].

The reference to Fig. 2 in the Outcomes section (page 5) should have been to Fig. 3.

The reference to Fig. 3 in the Prognostic factors section (page 6) should have been to Fig. 4 and the existing reference to Fig. 4 in that section should have been removed. doi:10.1007/s11060-015-1940-9.

Orin Bloch

orin.bloch@northwestern.edu

1 Department of Neurological Surgery, Northwestern University, Feinberg School of Medicine, 676 N. St Clair St, Suite 2210, Chicago, IL 60611-2911, USA

2 Department of Pathology, Northwestern University, Feinberg School of Medicine, Chicago, IL, USA 